\title{
Correlation between type of ground-based on b-value and the impact on buildings due to Sumatra earthquakes
}

\author{
Rafki Imani ${ }^{1, *}$, Utami Dewi Arman ${ }^{l}$, Wendi Boy ${ }^{l}$ \\ ${ }^{1}$ Department of Civil Engineering, University of Putra Indonesia “YPTK” Padang, Jl. Raya Lubuk Begalung, Padang, 25221, \\ West Sumatra, Indonesia
}

\begin{abstract}
The destructive earthquakes occurred in Sumatra are dominated by medium earthquakes, which generally come from the Sumatra fault and to have a direct impact on the land, buildings and around residential buildings. These earthquakes can be classified into high-frequency earthquakes with low-vibration periods. The hazards caused by the earthquake are mostly from damage and collapse of the residential buildings. This study is a literature review that aimed to observe the characteristics of rocks and ground in Sumatra areas based on b-value that obtained using seismicity estimation is related to the resistance of the earthquake on residential buildings. The b-values obtained from some previous researches so that they could be concluded, and then analyzed the type and condition of the local ground and then evaluated its effect on the surrounding buildings. Based on the outcomes, the estimation of b-value seismic parameters in Sumatra was found 0.34 to 0.5 . It means that the type of ground in areas of Sumatra has a hard rock layer. Physically, it has highfrequency earthquake waves; low vibration periods, spreading efficiently on hard layer and having a direct impact on local buildings consequently the risk of collapse building will be higher.
\end{abstract}

\section{Introduction}

Sumatra Island is a region in Indonesia with the potential and threat of earthquake hazard is quite high in the world. The boundary of the meeting of three plates is an area of destructive tectonic earthquake sources that come from subduction zones (Sumatra great fault) as shown in Fig. 1.

A series of the earthquake that occurred in Sumatra and surrounding areas has cause property losses, psychological impact and casualties either. For example, the Sumatra-Andaman earthquake on December 26, 2004, with a magnitude Mw 9.0 that followed by tsunami had stated more than 200 thousand people died [18], the Nias-Simelue earthquake on March 28, 2005, with magnitude $\mathrm{Mw} 8.7$ included the second major earthquake that occurred in this decade and also caused tsunami as well as The Padang earthquake on September 30, 2009, that was the most massive earthquake ever recorded in the history of seismicity in Sumatra.

The impact of the earthquake resulted in deaths, serious injuries, minor injuries and refugees who came from Padang Pariaman District and Padang City [3]. Most of the victims and losses due to the earthquake that occurred came from damage and collapse of the structure of the building. According to BMKG [7], there are several factors that affect occurrence of damage and collapse of building structures in one area due to the earthquake is; condition of the ground which buildings built, the characteristics of earthquake (such as seismic strength, frequency and earthquake vibration period) and location of epicenter or distance of hypocenter. Regarding the factors causing damage and collapse of the building, it is necessary to make mitigation efforts with earthquake-resistant building planning (earthquake engineering) so that casualties due to collapse buildings can be avoided. [10],[23].

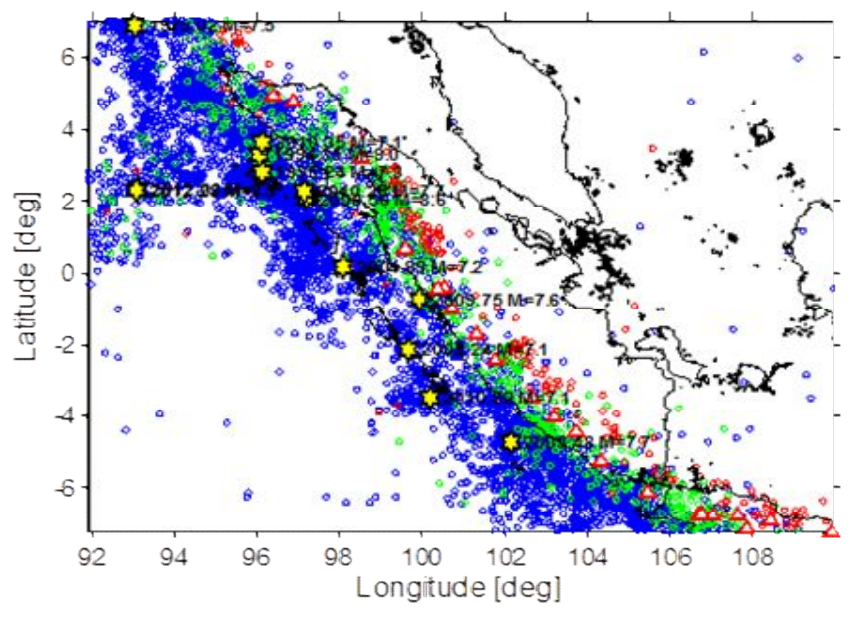

Fig. 1. Distribution of Earthquake ]Sources in the Region of Sumatra Period 1963 - 2013 [6].

One of the methods that used to evaluate the factors causing damage due to earthquake can be conducted by analyzing the tectonic parameter which is b-Value. 


\section{Seismicity of Sumatra}

Sumatra Island located within a ring of fire region of $5600 \mathrm{~km}$ that lie alongside from the Andaman Islands to Maluku till North Sulawesi, as well as adjacent to the subduction zone of Sumatra, has risen throughout this region having high seismic activity. The condition is compounded by the Sumatra fault line that extends along Sumatra Island and volcanic activity continuously increased.

The occurrence of an earthquake in Sumatra is due to its location at the Indo-Australia, and Eurasia plate meetings form subduction zone of Sumatra (Sundae subduction) that shown by Sundae Trench and identified as the epicenter of major earthquakes throughout the history of seismicity in Indonesia [20]. This condition is caused by the occurrence of fault or infiltration of the earthquake active plate so that Sumatra Island has a high level of earthquake vulnerability. Most of the significant earthquakes that ever occurred in Sumatra and surrounding area came from subduction zone of Sumatra. History records that seismicity in this zone is quite high with considerable strength, starting from the earthquake that occurred around The Mentawai Islands and Batu Islands in 1797 (Mw 8.3), 1833 ( Mw 9) and 1935 (Mw 7, 7), the earthquakes occurred around NiasSimeleu Island in 1861 (Mw 8.5) and 1907 (Mw 7.6), the earthquake occurred in Aceh-Andaman in 2004 (Mw 9.2) and the earthquake in 2005 occurred in Nias as well $(\mathrm{Mw} \mathrm{8,} \mathrm{7)} \mathrm{[12].}$

\section{Material and method}

\subsection{Calulatingstimasi parameter b-value}

The Commonly b-value parameter is aimed to know phenomena of the earthquake that will be occurred in the future and distribution of earthquake spreading. The commonly used method is, to the analysis of the magnitude-frequency correlation based on the proposed method by Gutenberg-Richter [5], to know the seismic activity in one region of the b-value parameter, as written as follows:

$$
\log N(M)=a-b M
$$

Which is $\mathrm{N}(\mathrm{M})$ is the number of earthquakes in magnitude $\mathrm{m}$; a-value is a seismic level of an area where the high a-values indicate that in the region has very active seismicity level and vice versa. Whereas, the bvalue related to the tectonic condition of the research area and depends on the properties of the local rock that describe local stress activity [21], which is shown by the fragility level of the rocks. The higher the b-value means, the greater fragility level of the rocks, and vice versa [2], [17],[22]. In addition, areas with having considerable heterogeneity correlated with high b-values [11]. Nevertheless, according to previous researches, the b-value of each region is constant and getting near to 1 [2],[26].
From Fig. 2, the b-value is determined by the slope of the line, which represents the relative probability of different earthquake occurrence in which the earthquake activity becomes smaller at increasing $b$-value. Statistically, the b-value can be determined with the following Maximum Likelihood Method (MLM) [1], [24]:

$$
b=\frac{0,434}{\bar{M}-M_{\min }}
$$

$\bar{M}_{\text {is }}$ the average magnitude and $M_{\min }$ is the minimum magnitude or magnitude completeness (Mc).

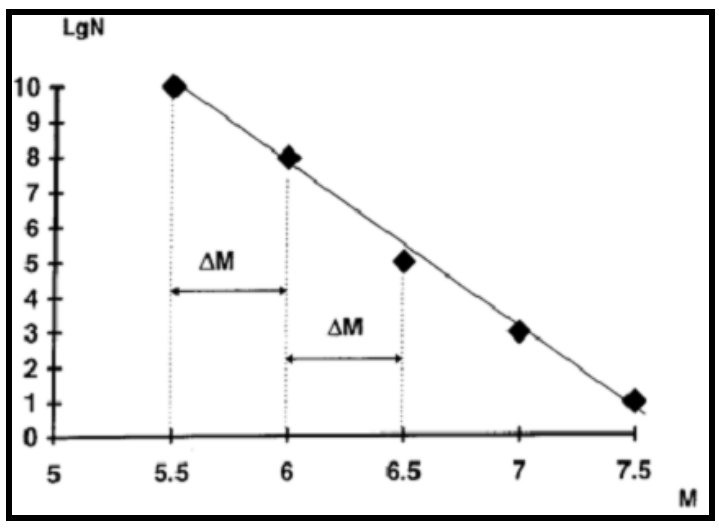

Fig. 2. Gutenberg-Richter Correlation

In related to seismic engineering, this calculation can be used to observe the geological condition of one area that consists of ground and rock characteristics, where the condition of this ground has a direct impact on the foundation of the building that is on it. Empirically, this correlation, resulting b-value that can be input in PSHA method of analysis of whole probability theory to determine the magnitude of earth acceleration due to earthquake occurred. Furthermore, the estimable acceleration scale is developed on seismic hazard map which is used as the basis for structural planning in one region.

\subsection{Methodology}

This study is a literature review based on previous researches in Sumatra. The data of b-value parameters that needed in this study were found from several related types of research that have been conducted to provide information about earthquake characteristics, such as the geological condition of rock structure in one region against earthquake disaster.

The data of earthquake which used is secondary data from earthquake recording catalogs that have occurred in surroundings of Sumatra, obtained from the USGS Preliminary National Earthquake Information Center (NEIC-USGS) catalog and earthquake recording catalog from BMKG. The main stages of data processing are as follows: 
1) Sorting data: This stage aims to uniform magnitude scale into magnitude moment $(\mathrm{Mw})$ and catalogs cluster.

2) Plotting frequency distribution of magnitude: To observe the completeness of earthquake data (Mc).

3) Analyzing b-value: Zmap Software.

\section{Analysis and discussion}

\section{$4.1 \mathrm{~b}$-Value of some previous researches in sumatra}

The b-value parameter data that used in this study obtained from several previous types of research with a time limit of the earthquake when the research was conducted. The data were as follows:

1. Research by Nuannin et al. [13] in Sumatra Andaman in 2005. The b-values obtained are about 1.1 to 1.78 .

2. Rohadi et al. [19], conducted a study to determine seism tectonic parameters in Sumatra areas with the data of earthquake until 2008. The b-values which they found ranged from about 0.5-1.5.

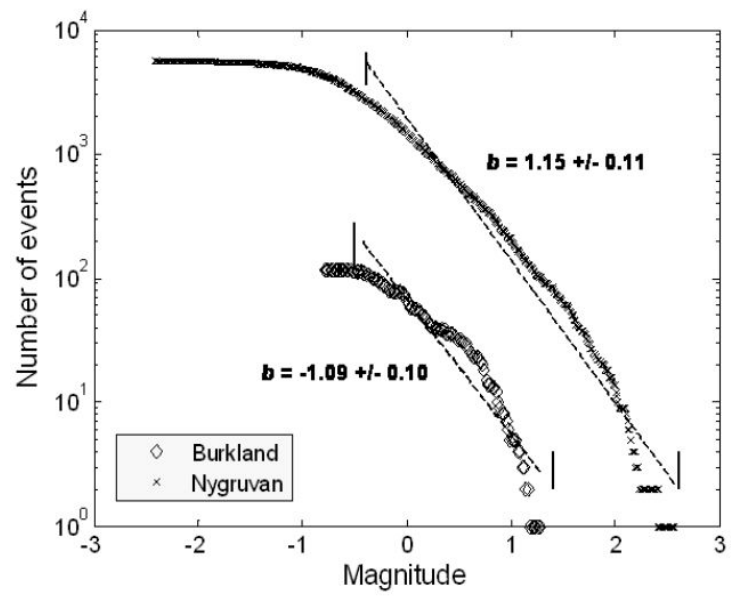

Fig. 3. b-Value Based on Frequency-Magnitude Distribution [13]

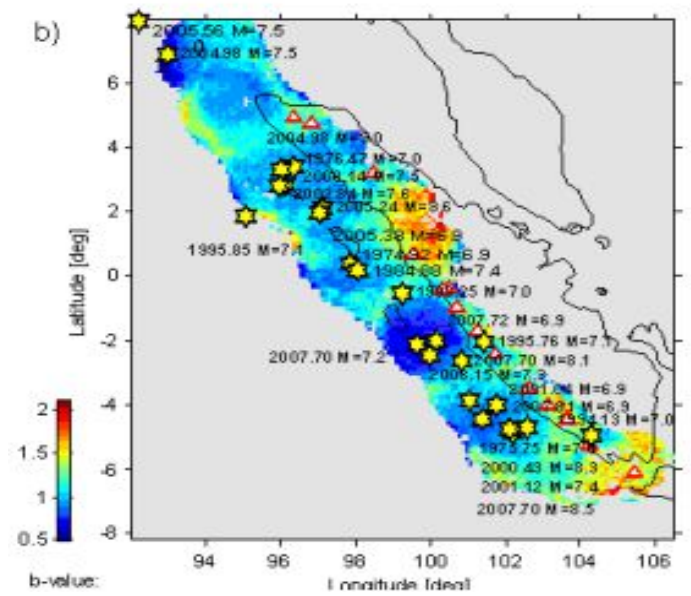

Fig. 4. b-value Variation in Sumatra Area (1973 - 2008)[19]
3. Putranda [16] conducted a study for seismicity analysis and repeatedly period of the earthquake in Sumatra in 2010. By the outcomes of mapping found a spatial variation of $b$-value for West Sumatra areas and ranged about 0.8 to 2.2 .

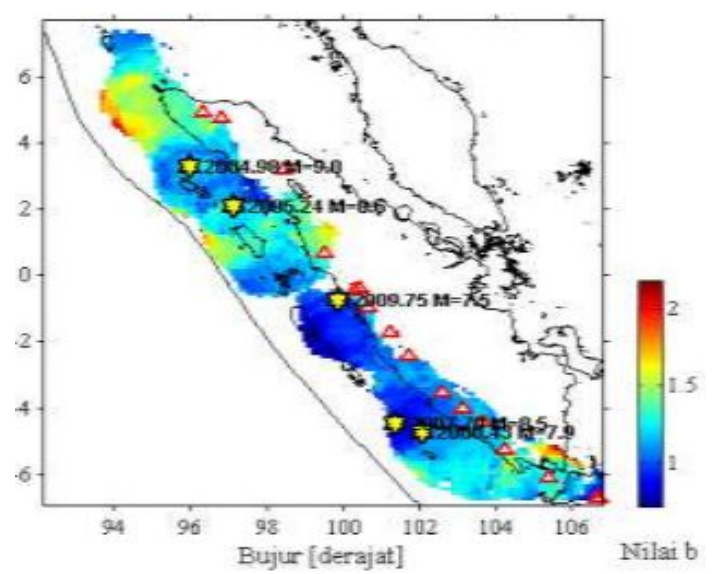

Fig. 5. Variation of b-values in Sumatra (1973 - 2009) [16]

4. Imani [6] in his research on seismicity study in Sumatra found the parameter b-value ranged from about 0.6 to 1.0 .

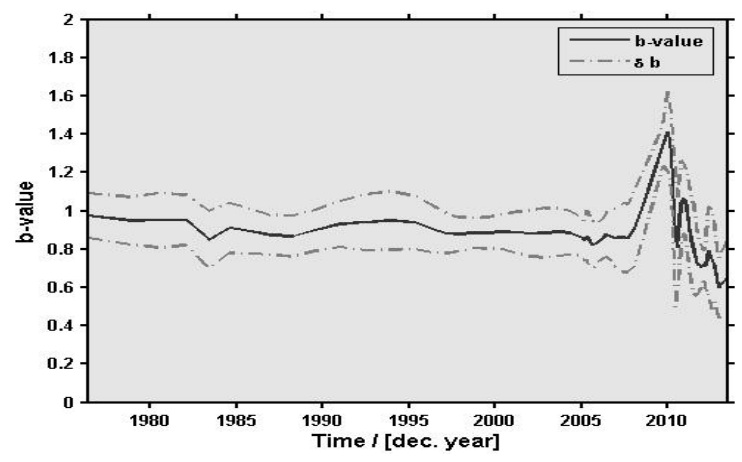

Fig. 6. Plotting Temporal Variation of Value-b vs. Time [6]

5. Asnita et al. [2] in their research on seismicity study in Sumatra found b-value ranged about 0.54 to 0.75 .

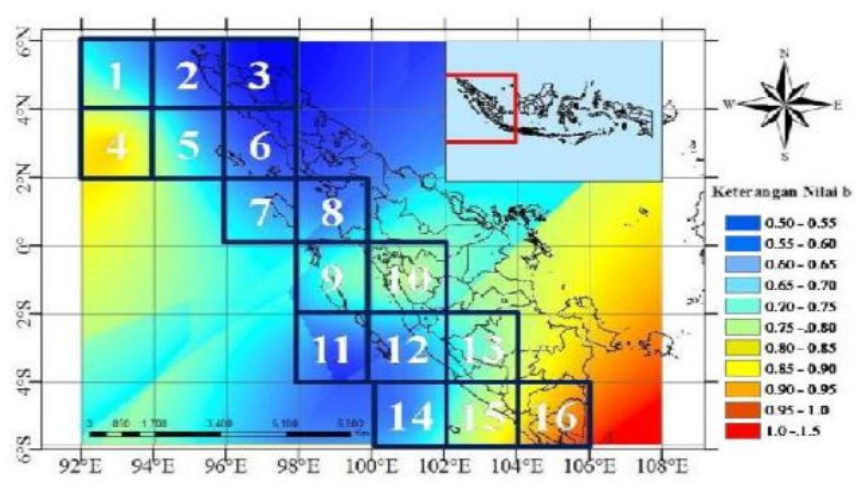

Fig. 7. The Variation of b-Value in Sumatra (1914-2014) [2]

6. Pailoplee [14] conducted a study in Sumatra-

Andaman. It found $b-V$ alue ranged about 0.34 to 0.74 . 


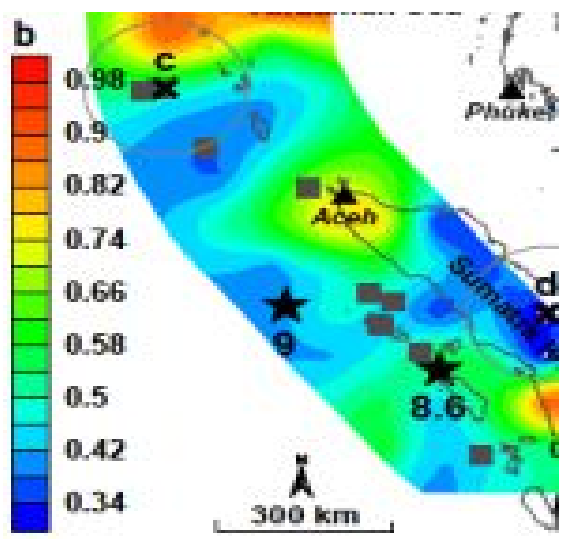

Fig. 8. The Variation of $b-V a l u e$ in Sumatra-Andaman Area (1976-2014)[14]

\subsection{The type of ground-based on b-value sumatra area}

The estimation of $b$-value in seismic engineering is used to observe the geological condition of one area such as ground type and characteristics of rock that can be input in PSHA method to determine the magnitude of earth acceleration due to the earthquake as fundamental for structure planning [19].

Based on some of the previous researches, that the bvalue seismic parameters in Sumatra are relatively small (b-values under 1). It means ground conditions in the Sumatra areas have hard rock properties so that stress that occurs in the rock becomes higher that will most likely raise massive earthquake in the future as a result of total energy accumulated long enough.

\subsection{The effect of ground type on building structure based on earthquake characteristics}

Geological conditions of ground type can affect characteristics of an earthquake such as strength, frequency and vibration period of earthquake waves. The type of sub-ground and bedrock of one area differs from one another, so that earthquake load that received by building due to motion ground coming from frequency and vibration period of earthquake waves is different as well. In-ground structure with having hard rock, highfrequency earthquake waves (low vibration period) will travel more efficiently than soft ground [8].

Based on experience, the destructive earthquakes that occur in Sumatra are generally dominated by small to medium strength earthquakes (Mw 4-5), mostly from Sumatra great fault on the mainland near the settlements. This type of earthquake is classified as an earthquake with characteristics that have a high frequency and low vibration period. Sub ground can affect the magnitude of earthquake load experienced by the structure of the building since the magnitude of natural vibration period of ground layer is indicated almost similar to natural vibration period of building structure above it [8].

Most of the settlements have rigid low-rise buildings structure. If the buildings are built on the hard ground and are hit by a high-frequency earthquake (low vibration period), then sub ground can increase earthquake load received by the buildings if possibly resonance occurred and earthquake risk to the residential building can become higher. Conversely, if the hard ground is built high-rise buildings, the effect of the earthquake that has high frequency will be less. This is because the high-rise buildings structure has high natural vibration period, which is inverse to the natural vibration period of hard ground.

\subsection{Influence of distance of earthquake center to building location based on ground condition}

The distance of the earthquake center (hypocenter) to buildings site includes factors that affect the size of the earthquake load would be received by buildings. Besides that, the earthquake in Sumatra's onshore fault, other earthquakes in Sumatra also came from subduction zones in the western ocean of Sumatra Island, which are a considerable distance from settlements of people on the mainland. These types of the earthquake are generally low-frequency earthquakes and high shaking period.

The risk of an earthquake with high vibration period tends to be directly proportional to soft ground properties, so if the soft ground is built high-rise building, then the risk of earthquake hazard is such as the collapse of the building would be higher and if possibly resonance happened.

The earthquake waves with high vibration period will tend to expand if it travels inside soft ground layers. This means that this type of earthquake load can reach a great distance to the building site if it travels within soft ground layers. The risk of the high-vibration period earthquake to high-rise buildings will also be higher since it has the same natural vibration period.

\section{Conclusions}

In general, b-value worth of earthquake area in Sumatra is found near almost 1 or less average of 1 . That is, a ground condition in Sumatra area has hard rock structure, which most of the small b-values occurred in the western part of Sumatra.

The high risks of the earthquake to settlements in Sumatra usually occurs as a result of the earthquake from Sumatra great fault located on the mainland near residential buildings, due to the type of ground in Sumatera area is hard ground and consequently the earthquake load to be larger.

We would like to thanks to previous researchers, which the variation of b-Value that obtained we use as data and references in this study.

\section{References}

1. Aki, K. (1965). Maximum Likelihood Estimate of b-values in The Formula $\log N=a-b M$ and Its Confidence Limits. Bull. Earthquake Res. Inst., Tokyo Univ. 43, 237-240. 
2. Asnita, W., Sugiyanto, D., Rusydy, I. (2016). Kajian Statistik Wilayah Sumatera. Journal Natural Vol 16 No. 2: 5 - 9.

3. BNPB \& Bappenas (2009). West Sumatra \& Jambi Natural Disasters: Damage, Loss \& Preliminary Needs Assessment. A Joint Report by The BNPB, Bappenas and The Provincial and District/City Governments of West Sumatra and Jambi and International Partners.

4. Delfebriyadi, R. Ferial., A. Y. Bestolova. (2011). Measurement of Padang City Spectra response using Probability Method., Jurnal Rekayasa Sipil., Vol. 7, No. 2.

5. Gutenberg, B., Richter, C. F. (1942). Earthquake Magnitude, Intensity, Energy and Acceleration. Bull. Seismol. Soc. Am., 32, pp. 163-191

6. Imani, R (2016). Seismicity Estimation and Validation of Earthquake Prediction Based on Probability Distribution Model as Earthquake Hazard Mitigation Efforts in Sumatra Region. Thesis. Master of Civil Engineering, Indonesian Islamic University, Yogyakarta.

7. Internet-1. http://www.bmkg.go.id

8. Internet-2. http://www.tekniksipil.org

9. Kramer, S. L. (1996). Geotechnical Earthquake Engineering. Prentice Hall, New Jersey, USA.

10. Makrup, L. (2011). Peak Ground Acceleration Curves and Seismic Hazard. Master of Civil Engineering, Indonesian Islamic University, Yogyakarta.

11. Mogi, K. (1962). Magnitude-Frequency Relationship for Elastic Shocks Accompanying Fractures of Various Materials and Some Related Problems in Earthquakes. Bull. Earthquake Res. Inst. Univ. Tokyo, 40: 831-883.

12. Natawidjaja, D. H. (2007). Earthquakes and Tsunamis in Sumatra and Efforts to Develop a Environment that Is Safe from Natural Disasters. LIPI, Jakarta.

13. Nuannin, P., Kulhanek, O., Persson, L. (2005). Spatial and Temporal b-value Anomalies Preceding The Devastating off Coast of NW Sumatra Earthquake of December 26, 2004. Geophys. Res. Let., 32, L11307.

14. Pailoplee, S. (2017). Probabilities of Earthquake Occurrences Along The Sumatra-Andaman Subduction Zone. Open Geosci. 2017. 9: 53 - 60.

15. Pasau, G., Tanauma, A. (2011). Modeling of Earthquake Source in North Sulawesi Region as an Earthquake Disaster Mitigation Effort. Research on Science and Technology and Art with the Cost of DIPA Unsrat. Science Scientific Journal, Vol. 11, No. 2, p. 202-209.

16. Putranda, E. (2010). Study of Time of Sumatran Earthquake Repetition Based on Seismic and Wavelet Statistics. Bachelor's Thesis 